\title{
Application of Internet of Things and Cloud Computing in the Logistics Equipment Support System
}

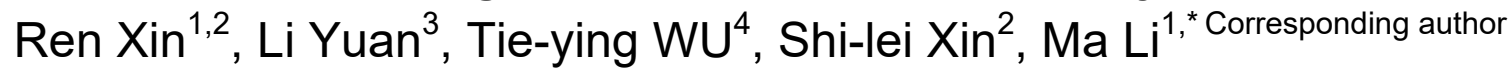 \\ 1. Naval Medical Research Institute, Shanghai, 200433, China \\ 2. Graduate School, National Defense University, Beijing, 100091, China \\ 3. Maintenance Management Teaching-research Office, Equipment Academy, Beijing, 101400, \\ China
}

4. Oncology Department, The 264th-Hospital of PLA, Taiyuan, 030000, China

Keywords: internet of things, cloud computing, logistics equipment, equipment support

\begin{abstract}
Along with the wide application of high and new technology, the modern war mode has gradually changed and tasks of logistics equipment support are increasing, which will put forward higher requirements for logistics equipment support sensitivity, rapidity, accuracy and visualization, and making further perfect logistics equipment support system is essential. This paper puts forward the concept of "intelligent logistics equipment support system" by applying internet of things and cloud computing technology to logistics equipment safeguard system construction, and also study its basic connotation, feasibility analysis, basic ideas of construction, and urging to walk intelligent development road of the future logistics equipment safeguard system construction to effectively improve the overall effectiveness of logistics equipment support.
\end{abstract}

\section{The theoretical introduction}

Cloud computing is a new concept in the field of information technology in recent years, and it can produce revolutionary influence on the network information system and strategic thinking. That is to say that a large number of computers and servers are connected into clusters of computer networks and the related rules is established to provide each kind of technical service to customers, and the network providing a variety of computing resources is known as the "cloud". The material and the internet can be connected with the full dimensional networking through information sensing devices such as laser scanners, RFID (radio frequency identification) equipment, GPS, infrared induction device based on established protocols in order to achieve information sharing and real-time transmission, and the internet of things can achieve the intelligent recognition, accurate positioning and monitoring network of material supply, mainly including three layer core network of perception layer, transport layer and application layer. Application layer of internet of things can establish the cloud computing platform so as to achieve a unified data collection, storage and service center, and it can spawn a modern cloud logistics. The interaction relationship between cloud computing and logistics network can be shown as in figure 1, and the main logistics equipment can be shown as in figure 2 .

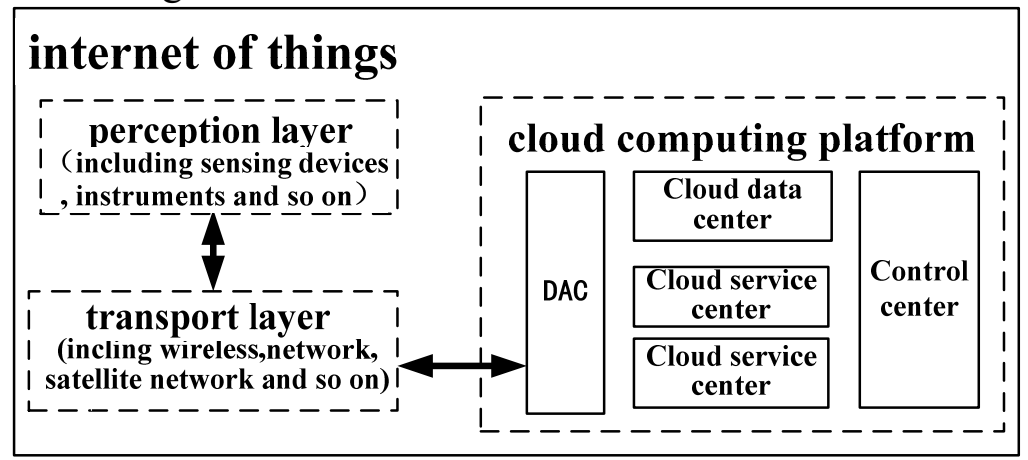

Fig. 1 Interaction relationship scheme of internet of things and cloud computing 


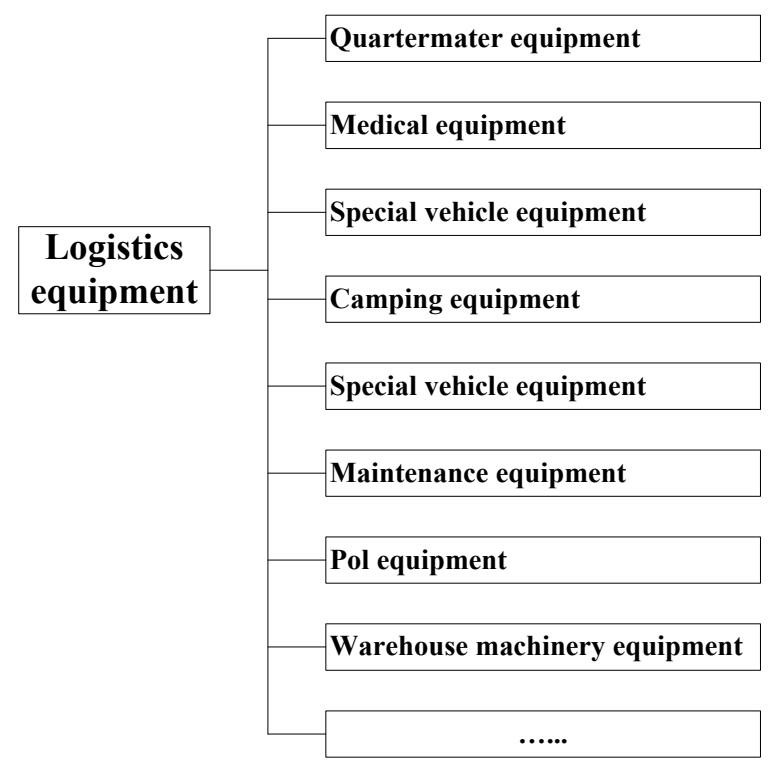

Fig.2 The sketch map of logistics equipment

\section{Feasibility analysis on the construction of "intelligent logistics equipment support system}

(1) The logistics equipment support system is becoming more and more perfect. With rapid development of modern high technology and the booming of new military changes in the world, the concept of operations, combat mode, system and weapon equipment architecture of armed forces around the world have made a series of changes in different degrees, and the logistical equipments also gradually develop in the direction of the multifunctional, seriation and module.

(2) The development of logistics equipment. With the wide application of electronic technology, computer technology, information technology, new materials technology and artificial intelligence technology, the logistics equipment develops in the direction of information, networking, intelligent. The continuous development of information, network and intelligence of logistics equipment has significantly improved the technical level and the support ability of the logistics equipment system.

(3) Experience for reference. The transition or transformation from mechanization logistical equipment system to the information logistics equipment system has been basically completed in the international military developed countries, and a large amount of fund and advanced technology can be used in the construction of things in order to improve the application level of cloud computing platform in information processing. The sensing device is installed in the logistics equipment in order to achieve the interconnection, perception and prediction of the battlefield environment and equipment system, and the mobile tracking system is installed in the main mobile logistics equipment in order to realize the real-time control of logistics equipment support activities which can improve the overall security efficiency for many times. The intelligent aided decision system is developed with the information technology and artificial intelligence technology in order to provide the decision support for logistical equipment security operations with the qualitative and quantitative analysis results.

\section{The research and exploration of the "intelligent logistics equipment support system" based on the cloud computing and the internet of things technology}

(1) To promote information construction and adhere to the dominant information. Information has become a key factor for enhancing the combat capability in the information battlefield conditions, and it will play a fundamental role in the future war. Logistics equipment support system is constructed adhere to the driving of information, and the integrated logistics equipment information system is gradually established and improved by increasing the new research and information reconstruction of existing security platform. Combining with internet technology and cloud computing platform, the information can quickly and effectively flow in order to achieve the 
interworking of logistics platform. The informationization and intelligent level of logistics equipment support system can be continuously improved and the information can become the booster of the "intelligent", which can build the foundation of the "intelligent" logistics equipment support system" and provide information assurance for the construction of "intelligent" logistics equipment support system.

(2) To promote the integration of system. The elements of logistics equipment support system are mutually integrated and penetrated, the link in logistics equipment support under the condition of informationization is no longer the separate chimney structure and it is the integrated network structure which is composed of the support elements through the information technology and computer network. The system integration technology is used to construct the intelligent logistics equipment support system, the mutual relations between the logistics equipment system can be integrated and optimized based on the information, and the decentralized logistics equipment will be connected together so as to achieve the modularization and integration of the logistics equipment system. The military logistical equipment should be cohered to implement the horizontal integration, the sensing equipment will be installed on the logistics equipment, the unified material encoding standard of logistics equipment can be established, and the networking and cloud computing platform of forces will be further improved. Through the optimization of the unction and structure of intelligent of logistics equipment support system and the connection with the operational equipment by using the data chain, the horizontal integration of operational equipment and logistical equipment can be achieved, the ability of logistics equipment information acquisition, battlefield awareness and protection can be comprehensively improved so as to enhance the overall logistics equipment support efficiency.

(3) To deepen the civil and military integration. The construction of intelligent logistics equipment support system should make full use of national logistics network, cloud computing platforms and other modern information technology, and the network terminal construction of the logistics equipment support system will be strengthened in order to achieve the resources information integration of the logistics equipment. The effective communication channels and communication mechanism between the army and the national operational department will be established, and the logistics equipment facilities can be deployed and the logistics equipment technology standard will be established so as to realize the real-time sensing of the logistics equipment support demand based on the foundation of information sharing and the whole course of support activities can be controlled in the development of military and civilian integration. By doing this, the ability generation model transformation of the military logistics equipment support will be effectively promoted.

(4) Adhere to conducting the trials first and based on step by step. In order to save resources construction and effectively verify the feasibility of intelligent logistical equipment system, the principles of conducting the trials first should be followed in constructing the of intelligent logistics equipment support system, and the related representative units should be selected as a pilot in the national and military systems. The construction is carried out step by step in accordance with the three levels of strategy, battle and tactics, and the networking and cloud computing information processing platform construction is further promoted at all levels and it can be gradually comprehensive expanded depending on the situation. In addition, the construction of intelligent logistics equipment support system is the innovative exploration of the application of modern networking and cloud computing technology in logistics equipment support, and the constructions of infrastructure, technology, organization system, legal system, personnel training and other elements have not been perfect. The construction is a complex system involving many factors and it cannot be done quickly, and it needs to constantly fumble and validate and a lot of technology, capital and human resources will be invested. The long-term planning will be carried out based on the actual national conditions and the military and the relationship between long-term development and current needs should be handled well, and the construction should be steadily implemented step by step on the basis of accumulation and the intelligent logistics equipment support system will be gradually constructed. Persisting in the course of sustainable development, the strategic objectives 
can be established in order to continuously improve the overall benefits of intelligent logistics equipment support system construction.

(5) To strengthen technical prevention and improve system security. The networking and cloud computing technology can be applied in the construction of intelligent logistics equipment support system, the sensitive, rapid, full visual and controllable function of logistics equipment support is achieved through data transmission network and navigation and positioning platform in the wartime and peacetime emergency support tasks. In the construction of intelligent logistics equipment support system, the security protection of network, communications, navigation and positioning and radio frequency identification system should be strengthened. Through the safe operation of the network communication and real-time data transmission system, the effectiveness of intelligent logistics equipment support system can be fully produced.

\section{Conclusions}

The intelligent logistics equipment support system is constructed based on networking and cloud computing platform and the networking and cloud computing platform are comprehensively used in the logistic equipment support, and the real-time sensing of logistics equipment support process and the whole visualization of support resources can be realized through the continuous acquisition and transmission of information in the cloud with all kinds of sensors and the communication network. The effectiveness of logistics equipment support can be fundamentally improved at the peacetime and wartime by enhancing the informationization level of logistics equipment support.

\section{References}

[1] Yang Zhenghong. Smart city: the application of big data, Internet of things and cloud computing [M]. Beijing: Tsinghua University press, 2014

[2] Zhao Peihua. An analysis of the "smart campus" based on the cloud computing [J]. Journal of Changzhou College of Information Technology, 2012(4):8-10.

[3] Chen Ming, Xu Dang. Research on the construction and development of intelligent campus based on the Internet of things [J]. Journal of distance education, 2012(4):61-62.

[4] Sun Limin, Shen Jie, Zhu Hongsong. From the cloud computing to the sea computing: the architecture of the Internet of things [J]. ZTE technology, 2011,17(1):3-7.

[5] Varia J. Cloud architectures-Amazon Web services[EB/OL]. http://acmbangalore.org / events/monthly-talk/may-2008-cloudarchitectures-amazon-web-services.html,2009-03-01. 